\title{
Detection of Beta Lactmase in Ampicilin Resistance Enterobacteriaceae Isolated from Human Stool in Ekiti State, Nigeria
}

\author{
O. K. Ekundayo* and A. K. Onifade \\ Department of Biology School of science College of Education Ikere Ekiti, EkitiState, Nigeria \\ *Corresponding author
}

\begin{abstract}
A B S T R A C T
This study was conducted to determine $\beta$-lactamase in ampicillin resistant members of the family Enterobacteriaceae isolated from human stool of apparently healthy human volunteer and sick humans' stool from Federal Teaching Hospital Ido (FTH) and

Keywords

$\beta$-lactamase,

Enterobacteriaceae,

Stools samples

Article Info

Accepted:

22 March 2020

Available Online:

10 April 2020

University Teaching Hospital Ado Ekiti in Ekiti State. Stools samples were collected and analyzed microbiologically using conventional techniques, antibiotics susceptibility testing by disc diffusion method and Double disc synergy test was used to determine $\beta$-lactamase producing bacterial isolates. The genetic basis of resistance was achieved by plasmid profiling and plasmid curing techniques. Four enteric bacteria, namely Escherichia coli, Klebsiella aerogenes, Salmonella typhi and Proteus vulgaris were isolated from the stool samples and majority of the bacterial isolate resistance is either plasmid or chromosomally mediated. The results showed that, extended spectrum $\beta$-lactamase (ESBL) producing bacteria can be found in apparently healthy human volunteer stool and major tertiary hospitals in the state. Therefore personal hygiene in our local canteen and eateries, proper hand washing at individual homes, proper laboratory diagnosis for any infection, appropriate prescription of drugs should be considered, infectious disease control of every hospital should be effective and the use of antibiotics in poultry farm should be regulated in Ekiti State as this will help to monitor the trend of ESBLs infection.
\end{abstract}

\section{Introduction}

Enterobacteriaceae is a group of Gramnegative bacteria which are straight rods and usually found in the gastrointestinal tract (GIT). Thus, members of this family are referred to as enteric bacteria. This family is the only representative in the order Enterobacteriales of the class Gammaproteobacteria in the phylum
Proteobacteria. Most Gram-negative bacteria include the species of Salmonella, Shigella, Yersinia, Klebsiella, Citrobacter, Enterobacter, Proteus, Serratia and Escherichia and others. Escherichia coli is one of the major enteric bacteria which serves as reservoir for resistance gene (Brinas et al., 2005). They are facultative anaerobes, oxidase-negative and catalase-positive, while some members are motile and grow well at 
$37^{\circ} \mathrm{C}$. They may be found in soil, water, food, human and animals. Most enteric bacterial infections are treated with $\beta$-lactam drug which include Ampicillin, Amoxicillin and Carbapenems (Rahal, 2005).

Ampicillin is one of the $\beta$-lactam drugs that has been used to treat bacterial infection and demonstrated activity against bacteria. Most strains of Pseudomonas, Klebsiella and Aerobacter are considered resistant to ampicillin. Additionally, resistance to ampicillin is seen in the species of Enterobacter, Citrobacter, Serratia, Salmonella, indole-positive Proteus and E. coli. Some of these bacteria have been reported to show resistance to two or more antibiotics (Rahal, 2005).

$\beta$-lactamases are enzymes produced by some bacteria and are responsible for resistance to $\beta$-lactam drugs like penicillin and cephalosporins. These $\beta$-lactam drugs have a common element in their molecular structure, a four-atom ring known as a $\beta$-lactam ring which is responsible for their bioactivity. This $\beta$-lactamase enzyme breaks open $\beta$-lactam ring, deactivating the molecules important for antibacterial properties. $\beta$-lactamases include extended spectrum $\beta$-lactamases (ESBLs) (Paterson and Bonomo, 2005). ESBLs are known as extended-spectrum $\beta$-lactamases because they are able to hydrolyze a wide range of $\beta$-lactam antibiotics than the simple parent $\beta$-lactamase from which they are derived (Bush, 2008). ESBLs are plasmid mediated enzymes which are frequently found in Enterobacteriaceae especially Escherichia coli (Paterson and Bonomo, 2005).

In the last decade, a variety of plasmidmediated $\beta$-lactamases have emerged in bacteria, resulting in reduced susceptibility to broad spectrum $\beta$-lactam. Extended spectrum $\beta$-lactamases are plasmid mediated enzymes that confer resistance to penicillin, third generation cephalosporins and aztreonam but are inhibited by clavulanic acid (Bush and Jacob, 2010). ESBLs are plasmid-encoded enzymes in Enterobacteriaceae, frequently found in Escherichia coli and Klebsiella pneumoniae, but also present in other members of this bacterial family such as Salmonella, Proteus, Enterobacter, Serratia, Citrobacter and Pseudomonas (Paterson and Bonomo, 2005).

ESBL- producing Escherichia coli have been isolated from food animals in many European countries and Nigeria especially in Ibadan (Furtini et al., 2011). In fact, poultries, cattle and farm animals are now recognized as important carriers of ESBL producing Escherichia coli and Salmonella spp (Carattoli, 2008). Similarly, there have been an increasing number of reports of ESBLproducing Escherichia coli being isolated from foods of animal origin (Bergenholtz et al., 2009). ESBL producing organisms have also been detected in a variety of foodproducing animal's poultry, food of animal origin and in human faecal (Mesa et al., 2006; Carattoli, 2008 and Cortes et al., 2010).

\section{Materials and Methods}

\section{Fecal samples}

Stool samples were collected from 54 apparently healthy volunteers and 142 sick humans from Ekiti State University Teaching Hospital, Ado Ekiti and Federal Medical Centre, Ido Ekiti. Collection of the samples was achieved with the approval of Ethical Committee in both institutions. Certified Medical Laboratory Scientist assisted in collecting the samples. The researcher seeks consent from the apparently healthy volunteer before collection of their stool samples. A sterile wire loop was used to pick stool samples and streak on prepared sterile MacConkey and Deoxycholate Agar 
and incubated at $37^{\circ} \mathrm{c}$ for $24 \mathrm{hrs}$ after $24 \mathrm{hrs}$, pure colonies were obtained. Isolated bacterial were characterized on the basis of colonial morphology, colour, edges and elevation. Microscopy (Gram staining reaction): Distinct colonies on agar plate were gram stained and they were observed under microscope using X100 objective with immersion oil (Cheesebrough, 2000). Bacteria which stained red were categorized as gramnegative bacteria and those that stained crystal violet were categorized as grampositive. Further characterization was done with Biochemical tests which include Catalase test, Motility test, Urease test, Citrate test, Oxidase test, Indole test, Voges Proskauer test, Methyl red test, TSI (Triple sugar iron) and $\mathrm{H}_{2} \mathrm{~S}$ (hydrogen sulphide) production test (Cheesebrough, 2000).

\section{Control strains}

The control stains that were used in the course of the research include Escherichia coli ATCC 25922 and Salmonella ATCC 6539. These American Type Culture Collections (Escherichia coli ATCC 25922 and Salmonella ATCC 6539) were purchased from Federal Institute of Industrial Research (FIRO) Oshodi, Lagos, Nigeria in a slope of nutrient agar and it was stored in the refrigerator at temperature of $4^{\circ} \mathrm{C}$.

\section{Antibiotics sensitivity testing}

Antibiotics susceptibility testing was performed using the disc diffusion method as described by Clinical Laboratory Standard institute CLSI (2014). Commercially prepared antibiotics disc was obtained from Oxoid (Basingstoke, Hampshire, UK). The antibiotics, their codes and concentration in $\mu \mathrm{g}$ are as follows: Aminoglycosides: Streptomycin (Str, $10 \mu \mathrm{g}$ ), Gentamycin (Gen, $10 \mu \mathrm{g}$ ), Macrolides: Erythromycin (Ery, 5 $\mu \mathrm{g})$, Phenicols: Chloramphenicol (Chl, 10 $\mu \mathrm{g})$, Tetracycline: tetracycline (Tet, $25 \mu \mathrm{g}) . \beta$ lactam drugs: Cloxacillin (Cxc, $5 \mu \mathrm{g}$ ), Penicillin (Pen,10 $\mu \mathrm{g}$ ), Ampicilin (Amp,10 $\mu \mathrm{g}$ ), Amoxicillin (Amx,25 $\mu \mathrm{g}$ ), Augmentin (Aug, $30 \mu \mathrm{g}$ ), Fluoroquinolone: Ofloxacin

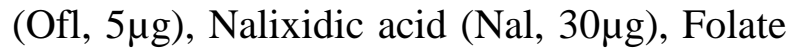
pathway inhibitor: Cotrimazole (Cot, 25 $\mu \mathrm{g}$ ) and other antibiotics like Nitrofurantoin (Nit, $200 \mu \mathrm{g})$.

Pure colonies on each bacterial isolate were inoculated into $5 \mathrm{ml}$ of sterile peptone water and incubated at $37^{\circ} \mathrm{C}$ for $6 \mathrm{~h}$. The turbidity was adjusted to match 0.5 McFarland standards and it was poured on the surface of solidified Mueller-Hinton agar. The peptone water was allowed to stay on the solidified agar and swirl to allow the bacterial spread on the agar for few seconds and then poured away before the commercially available multi-disk (AB Biodisk) for both grampositive and gram-negative were aseptically placed on the plates respectively.

The gram-positive disc which include

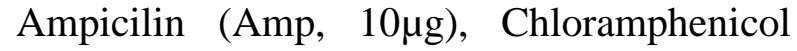

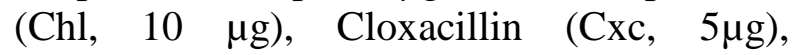
Erythromycin (Ery, 5 $\mu$ g), Gentamycin (Gen, $10 \mu \mathrm{g})$, Penicillin (Pen, 10 $\mu \mathrm{g})$, Streptomycin

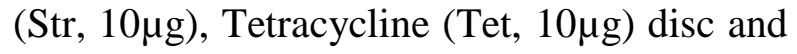
the gram-negative disc which include Augmenting (Aug, 30 $\mu$ g), Ofloxacin (Ofl,

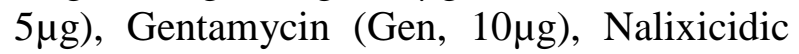
acid $(\mathrm{Nal}, 30 \mu \mathrm{g})$, Nitrofuratoin (Nit, 200 $\mu \mathrm{g}$ ), Cotrimazole (Cot, 25 $\mu \mathrm{g}$ ), Amoxicillin (Amx, $25 \mu \mathrm{g}$ ), Tetracycline (Tet, 25 $\mu \mathrm{g}$ ). After the disc has been aseptically placed on the agar using sterile forceps, the set up was incubated at $37^{\circ} \mathrm{C}$ for $24 \mathrm{~h}$. Zones of inhibition were measured after $24 \mathrm{~h}$ according to CLSI (2014) and organisms were classified as sensitive $(\mathrm{S})$, intermediate $(\mathrm{I})$, resistant $(\mathrm{R})$ and isolates resistant to three or more were classified as multi-drug resistant (MDR) (Ochei and Kolkhtar, 2000). 
Detection of ESBL-producing bacterial isolates resistant to Ampicillin using double disk

\section{Synergy test}

A 20ml portion of sterile Mueller-Hinton agar was poured on a sterile Petri dish and it was allowed to solidify. Isolate was inoculated into $5 \mathrm{ml}$ sterile peptone water. It was confirmed with 0.5 McFarland standards before it was poured on the solidified agar plate and swirled to ensure the sample spread through the entire plate before it was poured away. Oxoid single disk consisting of Amoxicillin- Clavulanic acid $(30 \mu g)$, Cefotaxitin (30 $\mu \mathrm{g})$, Ceftriaxone $(30 \mu \mathrm{g})$, Ceftadizime $(30 \mu \mathrm{g})$ were aseptically placed in $20 \mathrm{~mm}$ away from each other on the inoculated plate in such a way that the Amoxillin-clavulanic acid $(30 \mu \mathrm{g})$ was placed in the middle and it was surrounded with other antibiotics disc.

The plate was incubated at $37^{\circ} \mathrm{C}$ for $24 \mathrm{~h}$. The bacteria were considered to be producing ESBL when the zone of inhibition around any of the extended-spectrum $\beta$-lactamase discs showed a clear-cut increase towards the Amoxicillin-clavulanic acid disc (Pitout et al., 2003; Helene et al., 2011 and Ezekiel et al., 2011).

Genetic characterization of ESBLproducing bacterial isolates resistant to ampicillin by plasmid profiling techniques

\section{Plasmid analysis}

Plasmid analysis was carried out on bacterial isolates that are resistant to ampicillin which produces $\beta$-lactamase. This was carried out in order to know the molecular basis of resistance in some bacterial isolates. This was achieved with the help of Molecular Biology Laboratory of Nigeria Institute of Medical Research (NIMR), Yaba, Lagos.

\section{Plasmid extraction}

A $1.5 \mathrm{ml}$ portion of overnight culture was spinned at 12,000rpm for $1 \mathrm{~min}$ using a Micro centrifuge and the supernatant was decanted. A total of $300 \mu 1$ of TENS $(25 \mathrm{mM}$ Tris, $10 \mathrm{mM}$ EDTA (Ethylene diaminetetraacetic acid), $\mathrm{NaOH}$ (0.1 Sodium hydroxide) and SDS ( $0.5 \%$ sodium dodecyclsulphate) was added and then mixed together until it became sticky. A portion of $150 \mu 1$ of $3.0 \mathrm{M}$ sodium acetate ( $\mathrm{pH}$ 5.2) was added and the tube vortexes till it was completely mixed. The mixture was micro-centrifuged for $5 \mathrm{~min}$ at 13,000rpm to pellet i.e. (small particles created by compressing the original) cell debris and chromosomal DNA. Supernatant was transferred into a fresh tube (Eppendorf tube) and then mix with $800 \mu \mathrm{l}$ ice cold absolute ethanol and then centrifuged for $10 \mathrm{~min}$ to pellet plasmid DNA. The supernatant was discarded and the pellet was rinsed twice with $1 \mathrm{ml}$ of $70 \%$ ice cold ethanol and dried at $45^{\circ} \mathrm{C}$ for $15 \mathrm{~min}$. The dried pellet was re- suspended in 20-40 $\mu$ l of TE (Tris and EDTA) buffer and stored at $4^{\circ} \mathrm{C}$ for further use (Ezekiel et al., 2011)

\section{Agarose gel electrophoresis}

Agarose Gel Electrophoresis is a separation method that can be used to separate DNA based on their molecular weight. The concentration of Agarose used is dependent on the size of DNA to be separated but $0.8 \%$ Agarose is basically used for plasmid DNA. A $0.8 \mathrm{~g}$ portion of Agarose powder was mixed with 100mls of $1 \mathrm{X}$ TBE (Tris, Boric acid and EDTA) buffer. The mixture was dissolved by boiling on a hot plate using a magnetic stirrer, and later allowed to cool after which $10 \mu \mathrm{l}$ $(0.001 \mathrm{ml})$ of ethidium bromide was added. The mixture was poured on electrophoresis tank with comb in place to obtain a gel thickness and to avoid bubbles. It was allowed to solidify. The combs were removed 
and placed with the tray in the electrophoresis tank. 1X TBE (Tris base, Boric acid and EDTA) buffer was poured into the tank to ensure that the buffer covered the surface of the gel. A $15 \mu 1$ portion of plasmid DNA was mixed with $2 \mu$ l of loading dye was carefully loaded onto the well created by combs. Electrode was connected to the power pack in such a way that the negative terminal was at the end where the samples were loaded. Electrophoresis was run at $60-100 \mathrm{~V}$ until the loading dye (i.e. bromocresol purple) had migrated about three-quarter of the gel and the electrode was turned off. DNA bands were visualized and photograph using BioRad, Mini-Sub Get GT. The molecular weight of unknown plasmid DNA was extrapolated using the band mobilities in the gel (Ezekiel et al., 2011)

\section{Curing of plasmid DNA}

Curing of the plasmid was done to determine whether or not a plasmid encodes a trait that codes for antibiotics resistance or multiple antibiotic resistance. Curing was done using the sodium dodecyl sulphate (SDS). The isolate that showed resistance to Ampicillin and those that showed multiple resistance to different antibiotics due to plasmid bands were subjected to plasmid curing. One gram of sodium dodecyl sulphate (SDS) was added to $100 \mathrm{ml}$ of nutrient broth.

The solution was autoclaved at $121^{\circ} \mathrm{C}$ at $15 \mathrm{psi}$ for $15 \mathrm{~min}$. An overnight culture of the sample was standardized according to $0.5 \mathrm{McFarland}$ standard and $0.5 \mathrm{ml}$ from the standardize solution was pipette using Pasteur pipette into the $100 \mathrm{ml}$ sterile nutrient broth. This solution was incubated at $37^{\circ} \mathrm{C}$ for $24 \mathrm{~h}$. After incubation, the isolate was re-inoculated into a sterile nutrient broth and incubated for $24 \mathrm{~h}$ (Spengler et al., 2006; Charles et al., 2010; Annika et al., 2013).

\section{Post curing sensitivity testing}

The plasmid-cured isolates were tested against those antibiotics to which they were previously resistant. The diameter of zone of inhibition was measured using metre rule in $\mathrm{mm}$ and the zones were compared with Standard antibiotics chart (Ochei and Kolkhtar, 2000).

\section{Statistical analysis of data}

Data obtained from the study were subjected to analysis of variance (ANOVA) and treatment means were separated by Duncan's New Multiple Range Test using Statistical Analysis System Software (SAS) version 5.0.1.

\section{Results and Discussion}

Based on this study, Escherichia coli, Klebsiella aerogenes, Salmonella typhi and Proteus vulgaris from the stool samples were found to be highly resistant to Ampicillin $\left(97.75 \pm 0.01^{\mathrm{a}}\right)$, but sensitive to Nitrofurantoin $\left(82.16 \pm 0.01^{\mathrm{a}}\right)$, Nalidixic acid $\left(81.53 \pm 0.01^{\mathrm{b}}\right) \quad$ Gentamycin, $\quad\left(74.2 \pm 0.01^{\mathrm{b}}\right)$, Ofloxacin $\left(62.5 \pm 0.01^{\mathrm{c}}\right)$ and Cotrimazole $\left(60.50 \pm 001^{\mathrm{d}}\right)$. The percentage incidence of $\beta$ lactamase producing bacterial isolates in human fecal are represented in Table 1. The percentage of $\beta$ - lactamase producing Escherichia coli was high in sick human stools $(41.94 \%)$ as compared apparently healthy human stool volunteer $(6.45 \%)$. $\beta$ lactamase producing Salmonella typhi isolate from apparently healthy human stool $(12.5 \%)$ and sick human stool (12.5\%) was at same rate, Klebsiella aerogenes producing $\beta$ lactamase was high in apparently human stool $(40 \%)$ and non was found in sick human sick stool $(0 \%)$. Proteus vulgaris producing $\beta$ lactamase was seen in sick human stool $(14.29 \%)$ and none was found in apparently healthy human stool $(0 \%)$. 
Plate 1 shows the plasmid profile of Escherichia coli isolated from sick human stool (lanes 1-13) with exception in lane 2, 6 and 13 which showed no plasmid while the remaining lanes had similar plasmid with molecular weight of $23,130 \mathrm{bp}$ when compared with Hind III lambda as a molecular marker. However, Escherichia coli in lane 3 has 3 different bands with molecular weights $23,130 \mathrm{bp} ; 6,557 \mathrm{bp}$ and 2,322 bp.

Plasmid profile of Escherichia coli isolated from apparently healthy human stoolin lanes 28-29 have single plasmid band with molecular weight of $23,130 \mathrm{bp}$. Proteus vulgaris isolated from sick human stool in lane 32 have single plasmid band with molecular weight of 23,130bp. Also, Salmonella typhi isolated from food in lanes 39-41 showed single plasmid band with molecular weight of 23,130bp. Also, Salmonella typhi isolated from apparently healthy human (lane 42), sick human (lane 43) have similar plasmid with molecular weight of about 23, 130bp when compare with hind III lambda used as a molecular marker with the exception in lane 39 and 46 which showed no plasmid was represented in plate 2 .

The plasmid profile of Klebsiella aerogenes isolated from feces apparently healthy human (lanes 47-48) in plate 3 showed single plasmid band with molecular weight of $23,130 \mathrm{bp}$ with exception seen in lane 47 which showed no plasmid.

From the study pre and post curing sensitivity of bacterial isolates was carried out and it shows that, Escherichia coli (E1,E3, $\mathrm{E} 4, \mathrm{E} 5, \mathrm{E} 8, \mathrm{E} 9, \mathrm{E} 11$, and E12 isolated from sick human being were resistant to Ampicillin $\mathrm{R}$ before curing while after curing, E1,E3, E4,E5, E8, E9, E11, and E12 were sensitive to Ampicillin $\mathrm{S}$. It shows that the resistance to antibiotics is plasmid mediated.
Escherichia coli E7 and E10 isolated from sick human being were resistant to Ampicillin ${ }^{\mathrm{R}}$ before plasmid curing while after curing E7 and E10 were resistant to Ampicillin ${ }^{\mathrm{R}}$. The resistance to antibiotics is not plasmid mediated but rather chromosomal mediated.

Escherichia coli E28 and E29 isolated from healthy human being were resistant to Ampicillin ${ }^{\mathrm{R}}$ before plasmid curing while after plasmid curing E28 and E29 were sensitive to Ampicillin $\mathrm{S}$. This signifies that resistance to antibiotics is plasmid mediated.

Proteus vulgaris P32 (sick human stool), were resistant to Ampicillin $\mathrm{R}$ before plasmid curing while after plasmid curing $\mathrm{P} 32^{\mathrm{S}}$. Resistance to antibiotics is plasmid mediated.

Salmonella typhi S42 from sick human stool was resistant to ampicillin but became sensitive to ampicillin after plasmid curing. The resistance to antibiotics is plasmid mediated. Salmonella typhi S43 from sick human stool was resistant to Ampicillin ${ }^{\mathrm{R}}$ and Chloramphenicol ${ }^{\mathrm{R}}$ before curing while after curing S43 was resistant to Ampicillin ${ }^{\mathrm{R}}$. This shows that resistance to antibiotics is not plasmid mediated (chromosomal).

Klebsiella aerogenes K48, isolated from apparently healthy human stoolwas resistant Ampicillin ${ }^{\mathrm{R}}$ before curing while after curing $\mathrm{K} 48$, were sensitive to ampicillin $\mathrm{S}$. This shows that resistance to antibiotics is plasmid mediated.

Antibiotic resistance in bacteria has emerged as a medical challenge. This results from the speed at which bacteria multiply and are spread, and the ease with which they can change their genetic material or acquire new genes. They exert biochemical resistance by preventing entry of the drug, by rapidly extruding the drug, or by enzymatically inactivating the drug or altering its molecular 
target. The presence of antibiotics in the internal environments of human beings and animals provides a selective pressure for any resistant organisms to become predominant. In this study, four different enteric bacteria which include Escherichia coli, Salmonella typhi, Klebsiella aerogenes and Proteus vulgaris were isolated from human and are resistant to ampicillin which corroborates the findings of Rahal (2005) which says most strains of Pseudomonas, Klebsiella, Aerobacter, Enterobacter, Citrobacter, Serratia, Salmonella, Escherichia coli and indole-positive Proteus species are considered resistant to Ampicillin (Rahal, 2005).

Some drugs used for animals that are consumed as human food, such as cattle, pigs, chickens, fish, and others considering the extensive use of antibiotics in animal husbandry. Historically, this use has been little regulated, because very little restrictive legislation or regulatory limitations exist. These drugs can affect the meat, milk, and eggs produced from these animals and can be the source of "superbugs". For example, farm animals, particularly pigs, chicken are believed (though not proven) to be able to infect people with MRSA (Methicillin Resistant Staphylococcus aureus) (Schneider and Garrett, 2009) this may be the reason apparently healthy human showed ESBL producing isolates. Healthy people usually are not infected with ESBL but certain habitual acts like eating from canteens where personal hygiene is not practiced can make them carrier and people working in animal farm can make colonization or infection more likely (Dhillon and Clark, 2012).Most of all the isolates tested were susceptible to Nitrofurantoin, Nalidixic acid, Gentamycin, Cotrimazole and Ofloxacin which was in accordance with (Woodford et al., 2006) which says Treatment options for ESBL infections may include Nitrofurantoin and in desperation, Gentamycin injections may be used. Another reason for ESBL producing isolate seen in human stools may be due to use of antibiotics in food producing animals which also corroborates the report of Bradford (2001) which indicated an occurrence of resistance caused by ESBL has been linked to the use of antimicrobials in food producing animals, in particular 3rd generation cephalosporins. Studies have also shown that humans can be exposed to ESBL producing pathogens causing clinical illness via direct contact with infected animals, via contaminated food or indirectly through the environment. $\quad \beta$-lactamase have been frequently recovered from animals and food of animal origin in EU countries. These genes can be transferred to bacteria with potential to cause infections in humans (Bradford, 2001).

According to Health Protection Agency (2009) in United Kingdom which revealed that majority of apparently healthy individual with ESBL infection could be traced to the intake of contaminated water, consumption of contaminated food from canteens and food vendors. This study confirms that the percentage of fecal carrying ESBL producing Enterobacteriaceae ranged between $6.45 \%$ $40 \%$ across the isolates in apparently healthy humans i.e. non-hospitalized and $0 \%$ $41.94 \%$ in sick human stool i.e. hospitalized patients.

This might be as a result of their long time stay in the hospital facilities or as a result of antibiotics taken while in the hospital facilities. This is contrary to the report of (Ben-Ami et al., 2006; Valverde et al., 2008) in which ESBL producing enteric bacterial was 3.7-5.5\% in non-hospitalized patients and $10.8 \%$ in patients admitted to the hospital.

Based on this study, ESBL producing Enteric bacteria is more in sick human being stool than apparently healthy human stool and this might be due to their weakened immune 
system and exposure to long time antibiotics, long time stay in the hospital environment. This report is in accordance with the study of Ben-Ami et al., (2006) which says nursing home patients and hospital patient are more likely to be treated empirically with antibiotics, and thus on admission to a hospital to be more likely to possess an ESBL producing strain. Patient to patient transmission of ESBL producing organisms occurs via the hands of hospital staff, hospital equipment's. It is known that ESBL producing strains can survive in the hospital environment.

Plasmid has been documented to have encoded gene that provides resistance to occurring antibiotics in competitive environmental niche (Kroll et al., 2010). This study confirms that most resistance in this study was plasmid mediated. Findings from this study indicated that resistance shown by the bacterial isolates is mainly plasmid mediated. In addition, some of the bacterial isolates are chromosomal mediated. Although, most of the bacterial isolates carried plasmid bands but not all are responsible for the antibiotic's resistance. This is supported by (Thomas et al., 1998) who reported that plasmid mediated mechanism may increase the like hood of horizontal spread. Resistance of bacterial organism not due to plasmid or chromosome might be due to efflux pump mechanism (Poole, 2004) or other factors like mutation of genes encoding ribosomal protein which decrease permeability of the cell envelope in enteric bacteria (Isenerger et al., 2002). There is therefore no doubt that ESBL producing bacterial isolates can be found in apparently healthy human and sick human stool in Ekiti State, Nigeria.

Table.1 Percentage incidence of $\beta$-lactamase producing bacteria isolates in human stool in Ekiti state

\begin{tabular}{|l|c|c|c|c|}
\hline Samples & $\begin{array}{c}\text { Escherichia } \\
\text { coli }\end{array}$ & $\begin{array}{c}\text { Salmonella } \\
\text { typhi }\end{array}$ & $\begin{array}{c}\text { Klebsiella } \\
\text { aerogenes }\end{array}$ & $\begin{array}{c}\text { Proteus } \\
\text { vulgaris }\end{array}$ \\
\hline $\begin{array}{l}\text { Apparently healthy } \\
\text { human stool }\end{array}$ & $2(6.45)$ & $1(12.5)$ & $2(40)$ & $0(0)$ \\
\hline Sick human stool & $13(41.94)$ & $1(12.5)$ & $0(0)$ & $1(14.29)$ \\
\hline
\end{tabular}

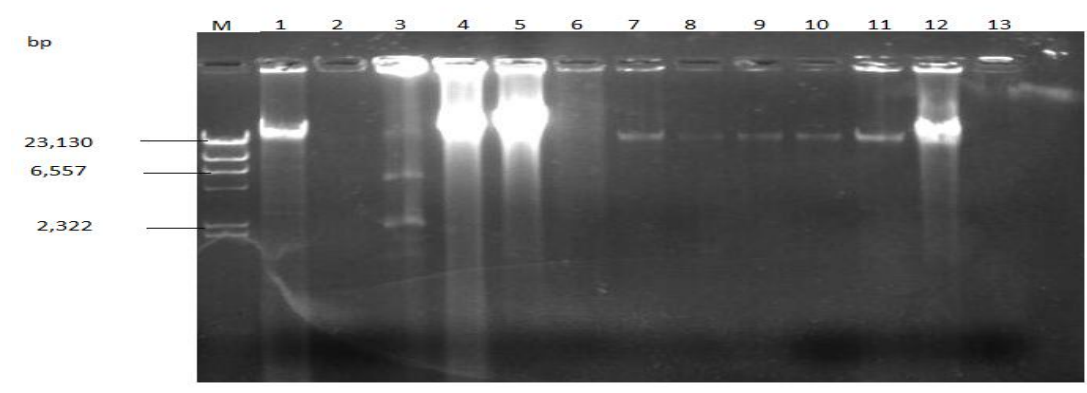

Plate.1 Photograph showing of plasmid profile of Escherichia coli isolated from the faeces of sick human (lane 1-13). Plasmid DNA on 0.8g Agarose, M-Molecular marker Hinda 111 lambda, Lane 1-13 (Escherichia coli), bp-Unit of molecular weight is base pair 


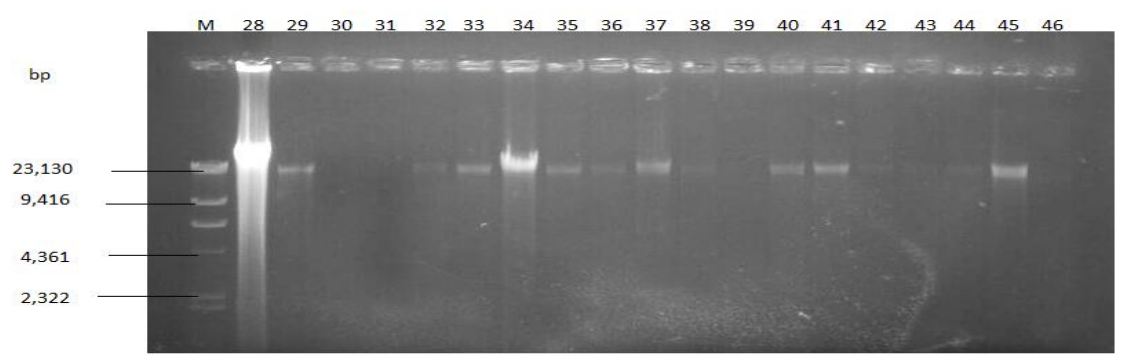

Plate.2 Photograph showing plasmid profile of Escherichia coli from apparently healthy human (lanes 28-29), Proteus vulgaris from the faeces of sick human (32), Salmonella typhi from apparently healthy human (lane 42), faceas of sick human (lane 43)

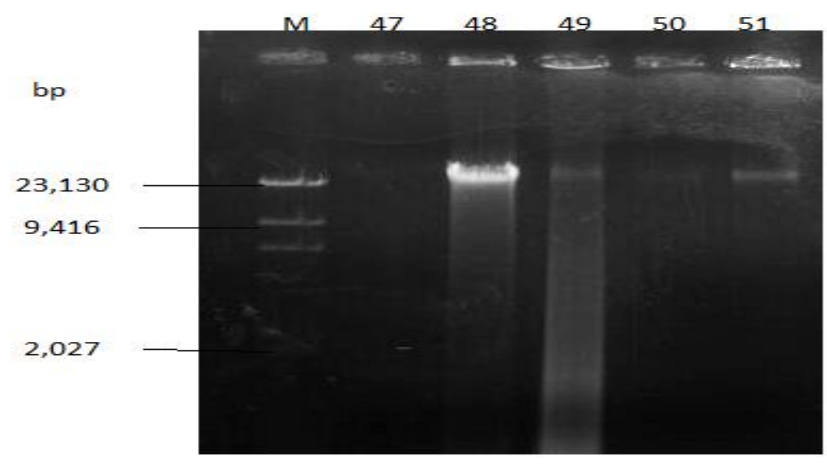

Plate.3 Photograph showing the plasmid profile of ESBL producing Klebsiella aerogenes isolated from faeces of apparently healthy human (lane 47-48) Plasmid DNA on 0.8g Agarose, M-Molecular marker Hinda 111 lambda, lane

Extended spectrum $\beta$-lactamase (ESBL) has undoubtedly become a widespread problem which has generated serious global health concern. These enzymes are becoming increasingly expressed by many strains of pathogenic bacteria with a potential for dissemination.

The fact that prevalence rates are rising globally, including hospital, in nonhospital settings, food, apparently healthy and sick subject, among chickens and even fish farming where chicken stool are used as fertilizer to boast the growth of fish is of great concern to public health at large. However, this study has revealed findings concerning $\beta$ lactamases producing organism can be isolated from, human especially apparently healthy human volunteer with little report and sick human Therefore, appropriate antimicrobial selection, personal hygiene and quality control should be encouraged in canteens, personal hygiene among health workers, proper diagnosis to ascertain the causative agent before prescription, ban the use of antibiotics in farm animals, over the counter prescription should totally be avoided, professional pharmacist should be employed and effective infection control procedures are the key partners in their control.

It is important to recall that antibiotics resistance profile and sensitivity profile in this study is to provide an updated data for clinician, Medical laboratory scientist and other health care workers in order to facilitate the use of appropriate and more effective 
treatment regimes. It has been noted that more research had been carried out on plasmid mediated resistance of enteric bacteria to antibiotic, effort should be made to research on the chromosomal mediated resistance of Enterobacteriaceae to antibiotics as reports on this aspect is limited. Above all, accelerated and continuous search for alternative remedy and more effective new antibiotics should be increased. Gentamycin, Nitrofurantoin, Nalidixic acid, Cotrimazole and Ofloxacin can be adopted in the treatment of ESBLs infection based on the findings from this study.

\section{References}

Ben-Ami, R.,Schwaber, M. J., Navon-Venezia, S., Schwartz, D., Giladi, M., Chmelnitsky, I., Leavitt, A., and Carmeli, Y. (2006). Influx of extended-spectrum beta-lactamase-producing

Enterobacteriaceae into the hospital. Clinical Infectious Disease, 42: 925-934.

Bergenholtz, R .D., Jorgensen, M. S., Hansen, L. H., Jensen, L.B., and Hasman, H. (2009). Characterization of genetic determinants of extended-spectrum cephalosporinases (ESCs) in Escherichia coli isolates from Danish and imported poultry meat. Journal of Antimicrobial Chemotherapy, 64: 207-209.

Bradford, P.A. (2001). Extended-spectrum $\beta$ lactamases in the 21stcentury characterization, epidemiology, and detection of this important resistance threat. Journal of Clinical Microbiology, 14: 933-951.

Brinas, L., Moreno, M. A., Teshager, T., Saenz, Y., Porrero, M.C., Dominguez, L. and Torres, C. (2005). Monitoring and characterization of extended-spectrum beta-lactamases in Escherichia coli strains from healthy and sick animals in Spain. Antimicrobial Agents Chemotherapy, 49: 1262-1264.

Bush, K. (2008). Extended-spectrum $\beta$ lactamases in North America, 1987-2006.
Clinical Microbiology and Infection, 14(1): 134-143.

Carattoli, A. (2008). Animal reservoirs for extended spectrum beta-lactamase producers. Clinical Microbiology Infection, 14:117-123.

Charles, O.E., Chukwuemeka, S. N., and Gugu, T.H.(2010). Antibiogram and plasmid profile of some multi-antibiotics resistant urinopathogens obtained from lcommunities of Southeastern, Nigeria. Journal of Medicine and Biomedical sciences, 2(4):152-159.

Cheesbrough, M. (2000). Microbiology test: District Laboratory Practice in tropical Countries. In: Cremer, A and Evan G. (eds). Cambridge University Press, UK. Pp: 1-226.

Clinical and Laboratory Standards Institute (2014). Performance standards for antimicrobial/susceptibility tests, Wayne, PA: CLSI.

Cortes, P., Blanc, V., Mora, A., Dahbi, G., Blanco, J. E., Blanco, M., Lopez, C., Andreu, A., Navarro, F., Alonso, M. P., Bou, G., Blanco, J. and Llagostera, M. (2010). Isolation and characterization of potentially pathogenic antimicrobialresistant Escherichia coli strains from chicken and pig farms in Spain. Application Environmental Microbiology, 76: 2799-2805.

Dhillon, R.H., and Clark J. (2012). ESBLs: a clear and present danger? Critical Care Research Practice, 1-11.

Ezekiel, C. N., Olarinmoye, A. O., Oyinloye, J. M., A, Olaoye, O. B. and Edun, A. O. (2011). Distribution, Antibiogram and multidrug resistance in Enterobacteriaceae from commercial poultry feeds in Nigeria. African Journal of Microbiology Research, 5(3):294-301.

Furtini, D., Fashae, K., Garcia-fernado, A., Villa, Z., and Carattoli, A. (2011). Plasmid mediated quinolones and $\beta$ lactamase in Escherichia coli from healthy animals from Nigeria. Journal of Antimicrobial Chemotherapy. (6):69-72.

Health Protection Agency (2009). General 
Information on Extended Spectrum BetaLactamases Frequently Asked Questions Description. Available from: www.hpa.org.uk/Topics/InfectiousDiseas es/InfectionsAZ/ESBLs/Generallinformat ion/. Accessed on 25/01/2013.

Helene, G., Laurence, D., Jean-luois, G., Vincent, J., and Jerome, R. (2011). Comparison of Nine Phenotypic Methods for detection of Extended-Spectrum $\beta$ lactamase production by Enterobacteriaceae. Journal of Clinical Microbiolog.49(3):1048-1057.

Isenberger, K. Hill, D. W., Jenkins, I.E. and Magee J.T. (2002). Clinical significance of the emergence of bacterial resistance in the hospital environment. Journal of Applied Microbiology, 92: 908-978.

Kroll, J., Klinter, S., Schneider, C., and Steinbuchel, A. (2010). Plasmid addition systems: perspective and application in biotechnology microbiology. Journal of Biotechnology, 3(6):634-657.

Mesa, R., Blanc, V., Saco, M., Lavilla, S., Prats, G., Miro, E., Navarro, F., Cortes, P, and Llagostera, M. (2006). ESBL- and plasmid class $\mathrm{C}$ beta-lactamase-producing E. coli strains isolated from poultry, pig and rabbit farms. Vetinary Microbiology, 118: 299-304.

Ochei, J. and Kolkhtar, A. (2000). Bacteriology: Medical Laboratory Science, theory and practice. In: Bulakh P.M and Deshmukh S.(eds). Tata McGraw-Hill publishing company limited New Delhi. PP. 525752.

Paterson, D. L., and Bonomo, R. A., (2005). Extended-spectrum beta-lactamases: a clinical update. Clinical Microbiolology, 18: $657-686$

Pitout, J. D., Reisbig, M. D., Venter, E. C., Church, D. L., and Hanson, N. D. (2003) Modification of the double disc test for detection of Enterobacteriaceae producing extended spectrum and AmpC $\beta$ lactamases. Journal of Clinical Microbiology, 41: 3933-3935.

Rahal, J.J. (2005). Extended spectrum ßlactamases: how big is the problem? Clinical Microbiology Infection; 6: 2-6.

Splengler, G., Molnar, A., Schelz, Z., Amaral, L., Sharpless, D., and Molnar, J.(2006). The mechanism of plasmid curing in bacteria. Current Drug target, 7(7): 823841.

Thomas, J. K., Forrest, A., Bhavnani, S. M. (1998). Pharmacodynamic Evaluation of Factors Associated with the Development of Bacterial Resistance in Acutely Ill Patients during Therapy. Antimicrobial Agents Chemotherapy, 42 (3): 521-527.

Valverde, A., Canton, R., Novais, A., Machado, E., Peixe, L., Baquero, F., and Coque, T. M. (2008). Prevalence and spread of extended-spectrum beta-lactamaseproducing Enterobacteriaceae in Europe. Clinical Microbiology Infection, 14 (1): 144-153.

Woodford, N., Ward, E. and Kaufmann, M. E. (2006). Molecular characterization of Escherichia coli isolates producing CTXM-15 extended-spectrum $\beta$-lactamase (ESBL) in the United Kingdom. Health Protection Agency. Retrieved 2006-1119.

\section{How to cite this article:}

Ekundayo, O. K. and Onifade, A. K. 2020. Detection of Beta Lactmase in Ampicilin Resistance Enterobacteriaceae Isolated from Human Stool in Ekiti State, Nigeria. Int.J.Curr.Microbiol.App.Sci. 9(04): 2514-2524. doi: https://doi.org/10.20546/ijcmas.2020.904.301 